\title{
Prevalence of Stunting among 6-59 Months Children and its Association with Water, Sanitation and Hygiene Practice in Urban Slums of Kathmandu, Nepal
}

\author{
Sarswoti Singh1, Nil P Dhital', Rajan Paudel', Dipak K Sah1, Arjun Hamal', Junu Shrestha² \\ ${ }^{1}$ Central Department of Public Health, Institute of Medicine, Tribhuvan University, Kathmandu, Nepal 2London \\ School of Hygiene and Tropical Medicine, University of London, London, United Kingdom
}

\section{Corresponding author:}

Sarswoti Singh, BPH, $\mathrm{MPH}$

Central Department of Public Health, Institute of Medicine, Tribhuvan University, Kathmandu, Nepal

Email:sarswoti_singh@hotmail.com

Submitted : Oct 5, 2020

Accepted : Nov 29, 2020

\begin{abstract}
Introduction

Childhood malnutrition is a critical public health concern in Nepal. Slums are supposed to have poor water, sanitation and hygiene practices. This study has aimed to examine association between water, sanitation and hygiene (WASH) variables and stunting among 6 to 59 months children of slums of Kathmandu metropolitan city.

\section{Methods}

Descriptive cross-sectional study design was employed where 335 households were included in the study. Data were collected using standard questionnaire and observation checklist. Weight and height of children were taken using seca digital weighing scale and wooden height board of UNICEF respectively. Anthropometric analysis was done using WHO Anthro version 3.2.2 software and other statistical analysis was conducted using SPSSversion 22 software.
\end{abstract}

\section{Results}

The prevalence of stunting was $23 \%$. Four out of five household (80\%) in slum used to drink water from unimproved source. Absence of handwashing station (AOR=2.109, 95\% Cl:1.05-3.27) and absence of water storage covering $(A O R=2.46,95 \% \mathrm{Cl}: 1.16-5.23)$ were found to be significantly contributing to stunting status.

\section{Conclusion}

This study highlights the importance of good WASH practices, and the potential of WASH interventions, to contribute for the improved childhood stunting living in urban slums in Nepal. Also, the findings recommend the need of strategies on purification of water, improvement of toilets, behaviour change and awareness related activities to improve the stunting among children.

\section{Keywords}

Hygiene, sanitation, slum, stunting, water 


\section{INTRODUCTION}

T he burden of malnutrition across the world is unacceptably high with 155 million stunted globally and 1 in 3 children (36\%) under age 5 is stunted in Nepal. ${ }^{2}$ World Health Organization (WHO) report says that half of under-nutrition is associated with disease caused by poor water, sanitation and hygiene situation of household and environment. ${ }^{1}$ Access to safe drinking water and sanitation service is a basic element of healthy communities and has an important positive impact on nutrition. Achieving the six global nutrition target 2025, as well as global goal for health and water, sanitation and hygiene (WASH) require greater investments in Nutrition and WASH. ${ }^{3}$

According to Nepal Demographic Health Survey (NDHS), about 14 million (37\%) people wash their hands with water and 12\% (3.4 million) with soap during critical times in Nepal. Nearly four out of five families (77\%) in Nepal drink water without appropriate water treatment practice prior to drinking. Overall, three in five (62\%) of households $(63 \%$ in rural areas and $61 \%$ in urban areas) use improved toilet facilities. ${ }^{2}$

Nepal has seen an impressive gain in health and nutritional status despite being in a state of political, economic and demographic transition ${ }^{4}$, however, in marginalized groups like slums, nutritional status, particularly in relation to the possible risk of morbidity and mortality in children has been less valued as a field of concern. Slum communities usually have low socio-economic status, lower land ownership, high rates of childbirth at home, and childhood illnesses, which might be accounted for the prevalence of under-nutritional status of the under 5 children. ${ }^{5}$ Children from poor households like slums have limited access to food and health services, making them susceptible to growth failures. ${ }^{6}$

However, water supply, sanitation condition of housing and hygiene behavior in slum settlement and nutritional status of children is a poorly researched area and because of the knowledge gap, WASH part is mostly ignored while addressing child undernutrition.

Therefore, this study was conducted to identify the nutritional status of 6 to 59 months children and its association with water sanitation and hygiene practice in slums of Kathmandu metropolitan city.

\section{METHODS}

The study was conducted in slum settlements of Kathmandu metropolitan city. There were a total of 26 slum settlements in the city. This was a crosssectional descriptive study applying quantitative approach to assess stunting in 6-59 months children and its association with WASH practices. The study duration was from December 2019 to July 2020.

A sample size of 475 was determined by using a formula ${ }^{7}$, where $z=1.96$ for $95 \%$ confidence interval, $p=0.29$ (2) with allowable error $(d)=0.05$, design effect=1.5 non-response rate $5 \%$ and the sample size was 498. Applying finite population correction, the final sample size was 335 . Two stage cluster random sampling was applied as sampling method. Sampling frame of 1023 children in 26 slums was obtained from albendazole and vitamin A target population of Kathmandu metropolitan city. Average children (6-59 months children) per cluster were $1023 / 26$ or 39.34 . In first stage, required 9 clusters $(335 / 39.34=8.52)$ were selected randomly. In second stage, 39 study populations were selected by using simple random sampling method from each of 9 clusters.

Data was collected through individual face to face interview using structured questionnaires with the mothers of the children and completing an observation checklist. The research tool was prepared by the researcher himself with reference to NDHS 2016. The tool was pretested in 5\% of sample in Lalitpur district. If there were more than one eligible child than one child was selected by lottery method. After the interview, anthropometric assessment (length, weight and height) of children aged 6 to 59 months was conducted. Height of children was measured using a height board of UNICEF to nearest $0.1 \mathrm{~cm}$ for the precision of the results. The weight of children was measured by Seca digital weighing machine to the nearest 100 grams or $0.1 \mathrm{~kg}$.

The bacteriological contamination in drinking water assessed by collecting drinking water samples from the household drinking water container at point of use. The sample was collected directly into H2S or PA Vials, filled upto the mark level and incubated for 48 hours. Change in color of water sample after incubation into dark blue marked the presence of contamination.

As classified by WHO Child Growth Standards 2006, children whose height for age (HAZ) was below minus two standard deviations (-2 SD) from the median of the reference population were considered short for their age (stunted) or chronically undernourished. ${ }^{8}$

The collected data was coded and entered in EpiData 3.1 computer software with check file and unique identifier. An anthropometric calculation was done by using WHO Anthro version 3.2.2 software. All data was exported to Statistical Package for Social Science (SPSS) version 22 software for further analysis. Univariate and multivariate analysis were carried out to know the association of stunting with WASH and socio-demographic characteristics. The statistical significance was considered at $p<$ 0.05 for $95 \%$ confidence interval of the Odds ratio. 
Ethical approval was taken from both Institutional Review Board of Institute of Medicine and National Health Research Council. Written informed consent was taken from mother or care-taker.

\section{RESULTS}

The average age of the mothers participating in the study was $27.34 \pm 5.70$ years while that of children was $29.49 \pm 15.31$ months. Seven respondents $(2.1 \%)$ were care takers. More than half $(57 \%)$ of the children selected for the study were male. Almost half $(49.3 \%)$ of the mothers had only one child, where one-third mothers had 2 children. The average age at first birth was $21.35 \pm 3.95$ years.

Table 2 represents the health status of the child participating in the study. When asked to recall any illness on child in 2 weeks prior to the study, more than half $(51.6 \%)$ of the total children had illnesses 2 weeks prior to the study. One in two mothers sought for treatment of their ill child at health facility, while 46.2 percent took medicines from pharmacies. Among those who visited health facility for the treatment, more than half ill children (50.1\%) were diagnosed with diarrhea.

Table 3 reveals the information about the water, sanitation and hygiene related characteristics of the households involved in study.

Table 1. Socio-demographic characteristics of respondents

\begin{tabular}{lc}
\hline \multicolumn{1}{c}{ Characteristics } & Number (\%) \\
\hline $\begin{array}{l}\text { Age of the mother } \\
15-19\end{array}$ & $12(3.6)$ \\
$20-24$ & $100(29.9)$ \\
$25-29$ & $115(34.3)$ \\
$30+$ & $108(32.2)$ \\
Age of the child (months) & \\
$\leq-11$ & $48(14.3)$ \\
$12-23$ & $85(25.4)$ \\
$24-35$ & $81(24.2)$ \\
$36-47$ & $59(17.6)$ \\
$48-\geq$ & $62(18.5)$ \\
Caste of the family & \\
Janajati & $184(54.9)$ \\
Dalit & $75(22.4)$ \\
Brahmin and Chettri & $53(15.8)$ \\
Other (Madeshi and Muslim) & $23(6.9)$ \\
Sex of the child & \\
Male & $191(57.0)$ \\
Female & $144(43.0)$ \\
Parity & \\
1 & $165(49.3)$ \\
2 & $121(36.1)$ \\
$\geq 3$ & $49(14.6)$ \\
\hline
\end{tabular}

Table 2. Health status of the children

\begin{tabular}{lc}
\hline \multicolumn{1}{c}{ Characteristics } & Number (\%) \\
\hline Recall illness in last 2 weeks & $173(51.6)$ \\
Place for treatment $(n=173)$ & \\
Visited health facility & $83(48.0)$ \\
Medicine taken from medical & $80(46.2)$ \\
Treated at home & $10(5.8)$ \\
Diagnosed disease( $n=83)$ & \\
Diarrhoea & $42(50.1)$ \\
Amoebic dysentery & $11(13.2)$ \\
Common cold & $20(24.1)$ \\
Others & $10(12.6)$ \\
\hline
\end{tabular}

Most of the households (81.8\%) had unprotected source of water, while less than half $(41.5 \%)$ of the households didn't use any methods of purification before drinking or using the water for cooking purposes. Only $11.3 \%$ had not covered their water storage. The water quality test showed that nearly two-third $(62.1 \%)$ of the household had contaminated drinking water.

Most of the households (94.6\%) had toilet, of which eighty three percent (83\%) of those were of improved type. More than half of the households $(52.5 \%)$ had handwashing station in their houses. Only one third (35\%) of the households segregated the solid waste. Solid waste from $53 \%$ households was collected by municipal vehicle while around one-fifth $(21.5 \%)$ of the households just threw the waste in open place. As per findings from observation checklist, more than fifty percent (55.8 $\%)$ toilets were found clean. The prevalence of stunting was $23 \%(95 \% \mathrm{Cl}: 18.63 \%-27.91 \%)$ in the slums.

Table 4 shows the multivariate analysis for stunting. On multivariate analysis, availability of handwashing station and covering of water storage container were found significantly associated with stunting. Having handwashing station decreased the odds of being stunted by 0.47 times ( $A O R=0.47,95 \%$ $\mathrm{Cl}: 0.30-0.95)$, while covering the water storage decreased the odds of being stunted by 0.41 times (AOR=0.40, 95\% Cl: 0.19-0.86). The Nagelkerke R square value of 0.12 indicates that $12.2 \%$ change in the dependent variable (stunting) was explained by the independent variables.

All of the study variables included in regression analysis had variance inflation factor (VIF) $<10$. Based on the above findings, the logistic regression equation for predicting stunting status from the independent variables can be derived as follows: where, $\log (p / 1-p)=-1.77-0.75 x_{1}-0.91 x_{2}$

$\mathrm{x}_{1}=$ availability of handwashing station, $\mathrm{x}_{2}=$ availability of coverage in water storage container and $\mathrm{p}=$ prevalence of stunting. 
Table 3. Characteristics related to water, sanitation and hygiene practice $(n=335)$

\begin{tabular}{lc}
\hline \multicolumn{1}{c}{ Characteristics } & Number (\%) \\
\hline Source of drinking water & \\
Unprotected & $274(81.8)$ \\
Protected & $61(18.2)$ \\
Purification methods & \\
Boiling & $126(37.6)$ \\
Use of filter & $51(15.2)$ \\
Others & $19(5.7)$ \\
No Purification & $139(41.5)$ \\
Water storage & \\
Covered & $297(88.7)$ \\
Not covered & $38(11.3)$ \\
Drinking water quality test & \\
Safe & $127(37.9)$ \\
Contaminated & $208(62.1)$ \\
Presence of toilet & \\
Yes & $317(94.6)$ \\
Type of toilet & \\
Improved & \\
Unimproved & \\
Handwashing station & $54(17.0)$ \\
Yes & \\
Segregation of solid waste & $175(52.5)$ \\
Yes & \\
Solid waste disposal & $117(34.9)$ \\
Collected by municipal vehicle & $178(53.1)$ \\
Burnt & $85(25.4)$ \\
Thrown in open place & $72(21.5)$ \\
\hline
\end{tabular}

\section{DISCUSSION}

Our study showed significant negative association between stunting and presence of handwashing station and covering water storage. The prevalence of stunting $(23 \%)$ as obtained in this study was relatively lower than the national surveys conducted. 2,9 NDHS 2016 has reported 36 percent of children under age 5 to be stunted. ${ }^{2}$ However, the stunting prevalence are consistent with findings from NMICS 2019 which shows 22.9 prevalence of stunting in Bagmati province. ${ }^{9}$ Overall, a higher risk of stunting among children was seen in the families with no handwashing station, and not covering the water storage container.

Mother's age was significantly associated with stunting and with increasing age there was increase in odds of child being stunted; however, it was not seen in multivariate analysis. These findings were similar to the NDHS findings as well as surveys done in Pakistan. 10,11 However, with increasing age at marriage of the mother, there was decrease in odds of child having under-nutritional deficiencies. This suggests that young women are still at developmental phase and they still need time for their own growth. Also, the children from young mothers are at risk of not being properly breastfed due to low milk supply. ${ }^{12,13}$

In this study, children aged 24 to 35 months were more likely to be stunted than the children of other ages. These findings are consistent with the studies done in Nepa ${ }^{11,14}$, Laos $^{15}, K_{\text {Kenya }}{ }^{16}$, Pakistan $^{10}$. Nepali context has tradition of mothers giving less attention to their children after they reach 2 years of age, thus transferring responsibility of caregiver to elder siblings and other members of the family,

Table 4. Association of significant characteristics with stunting status

\begin{tabular}{|c|c|c|c|}
\hline \multirow{2}{*}{ Characteristics } & \multicolumn{2}{|c|}{ Stunting } & \multirow{2}{*}{$\mathrm{p}$-value } \\
\hline & COR $(95 \% \mathrm{CI})$ & AOR $(95 \% \mathrm{CI})$ & \\
\hline Age of the mother & $1.05(1.07-1.09)$ & $1.04(0.99-1.10)$ & 0.09 \\
\hline No. of children & $1.26(1.012-1.57$ & $1.00(0.77-1.30)$ & 0.97 \\
\hline Age of child & $1.01(1.00-1.04)$ & 1.01 (0.99-1.03) & 0.17 \\
\hline $\begin{array}{l}\text { Handwashing station } \\
\text { No } \\
\text { Yes }\end{array}$ & $\begin{array}{c}1 \\
0.43(0.25-0.73)\end{array}$ & $\begin{array}{c}1 \\
0.47(0.305-0.95)\end{array}$ & $0.008^{*}$ \\
\hline $\begin{array}{l}\text { Management of solid wa } \\
\text { By municipal vehicle } \\
\text { Burn } \\
\text { Throw in open place }\end{array}$ & $\begin{array}{c}1 \\
0.66(0.33-1.27) \\
2.02(1.14-3.74)\end{array}$ & $\begin{array}{c}1 \\
0.78(0.36-1.55) \\
1.63(0.86-3.07)\end{array}$ & $\begin{array}{l}0.45 \\
0.13\end{array}$ \\
\hline $\begin{array}{l}\text { Covering of water storag } \\
\text { No } \\
\text { Yes }\end{array}$ & $\begin{array}{c}1 \\
0.45(0.19-0.81)\end{array}$ & $\begin{array}{c}1 \\
0.45(0.11-0.82)\end{array}$ & $0.02 *$ \\
\hline
\end{tabular}


which leads to poor feeding and hygiene practices, thus increasing the chances of child having under nutritional deficiencies. ${ }^{14}$

The availability of improved toilet, protected water source, purification of water, availability of handwashing station and similar health and hygiene behaviors have positive consequences on the nutritional status of the children. ${ }^{17}$ Poor hygiene and sanitation lead to diarrhoeal disease. A case control study conducted in Nepal found that having diarrhea in children one or more times in past two months was 7.46 times higher risk of stunting as compared to normal children. ${ }^{18}$ This supports the finding of this study that absence of handwashing station at home means there might be less handwashing practice among caregivers, thus increase the risk of childhood stunting. This also supports the fact that hands are carriers of various pathogens which cause diarrhoea and not keeping them clean contributes to illness in their children. Studies suggest that cleaning the hands interrupt the transmission close to zero, only through rubbing and rinsing action. ${ }^{19}$ Being an international agenda influencing the hygiene behavior in underdeveloped and developing countries like Nepal, handwashing is clearly influencing the childhood nutritional status. ${ }^{20}$

Thus, the study shows that improved sanitation and hygiene practices can contribute to the reduction in prevalence of stunting. Standard living conditions such as having improved toilets, having handwashing station, proper purification of water, and so on, can contribute to decrease the burden of under nutritional status of the under 5-year-old children. This study has some limitations. Some of the information was obtained through questionnaires and relied on mother's or care taker's self-report. This implies that respondent's views may be subjected to recall bias. Birth certificate of children was observed to find exact date of childbirth that helped to reduce some recall bias. This study has considered only WASH behaviors with childhood stunting however, stunting is influenced by many other factors. As this study was restricted to Kathmandu urban slums based on small sample size, the findings of this study should be generalized cautiously in other slum areas.

\section{CONCLUSION}

Around $23 \%$ of the children living in slum of Kathmandu metropolitan city are found stunted. Around four out of five families in slum use to drink water from unprotected sources. Poor WASH conditions are found to be significantly contributing to increase the stunting. Maternal and sociodemographic characteristics such as early marriage, increasing number of family members, age of the child, no. of children also contribute to increasing prevalence of the stunting in the slums. In order to reduce the burden of early stunting, the strategies which are focused on accessibility of clean drinking water, improvement of toilets, management of waste and awareness related to handwashing are needed.

\section{CONFLICT OF INTEREST}

None declared.

\section{REFERENCES}

1. World Health Organization. Improving nutrition outcomes with better water, sanitation and hygiene: practical solutions for policies and programmes. WHO. 2015.

2. Ministry of Health Nepal, New ERA and ICF. Nepal demographic and health survey. MOH. 2016.

3. Scaling Up Nutrition. Integrated WASH and Nutrition actions [Online]. Scaling Up Nutrition; 2015 [cited 202029 July]. Available from: https://scalingupnutrition.org/nutrition/integrating-washand-nutrition-actions/.

4. Devkota MD, Adhikari RK, Upreti SR. Stunting in Nepal: looking back, looking ahead. Maternal \& child nutrition. 2016;12:257.

5. Acharya P, Khanal $V$. The effect of mother's educational status on early initiation of breastfeeding: further analysis of three consecutive Nepal Demographic and Health Surveys. BMC Public Health. 2015;15(1):1069.

6. Chowdhury MRK, Rahman MS, et al. Risk factors for child malnutrition in Bangladesh: a multilevel analysis of a nationwide population-based survey. The Journal of pediatrics. 2016;172:194201.

7. Rosner B. Fundamentals of biostatistics: Nelson Education; 2015.

8. Group WMGRS. WHO Child Growth Standards based on length/ height, weight and age. Acta paediatrica (Oslo, Norway: 1992) Supplement. 2006;450:76.

9. Central Bureau of Statistics. Nepal Multiple Indicator Cluster Survey 2014, Final Report. Central Bureau of Statistics and UNICEF Nepal Kathmandu, Nepal; 2015.

10. Khan S, Zaheer S, Safdar NF. Determinants of stunting, underweight and wasting among children $<5$ years of age: evidence from 20122013 Pakistan demographic and health survey. BMC Public Health. 2019;19(1):358.

11. Adhikari RP, Shrestha ML, Acharya A, et al. Determinants of stunting among children aged 0-59 months in Nepal: findings from Nepal Demographic and health Survey, 2006, 2011, and 2016. BMC nutrition. 2019;5(1):37.

12. Raj A, Saggurti N, Winter $M$, et al. The effect of maternal child marriage on morbidity and mortality of children under 5 in India: cross sectional study of a nationally representative sample. Bmj. 2010;340.

13. King JC. The risk of maternal nutritional depletion and poor outcomes increases in early or closely spaced pregnancies. The Journal of nutrition. 2003;133(5):1732S-6S.

14. Adhikari D, Khatri RB, Paudel YR, et al. Factors associated with Underweight among Under-Five children in eastern Nepal: Community-Based cross-sectional study. Frontiers in Public Health. 2017; 5:350.

15. Phengxay M, Ali M, Yagyu F, et al. Risk factors for protein-energy malnutrition in children under 5 years: study from Luangprabang province, Laos. Pediatrics International. 2007;49(2):260-5.

16. Olack B, Burke $H$, Cosmas $L$, et al. Nutritional status of under-five children living in an informal urban settlement in Nairobi, Kenya. Journal of health, population, and nutrition. 2011;29(4):357.

17. Shrestha SK, Vicendese D, Erbas B. Water, sanitation and hygiene 
practices associated with improved height-for-age, weight-forheight and weight-for-age z-scores among under-five children in Nepal. BMC pediatrics. 2020;20(1):1-10.

18. Paudel R, Pradhan B, Wagle RR, et al. Risk Factors for Stunting Among Children: A Community Based Case Control Study in Nepal. Kathmandu Univ Med J. 2012;39(3):18-24.
19. Brown J, Cairncross S, Ensink JH. Water, sanitation, hygiene and enteric infections in children. Archives of disease in childhood. 2013;98(8):629-34.

20. Shiwakoti R, Devkota M, Paudel R. Women's empowerment and nutritional status of their children: A community-based study from villages of Bhaktapur District, Nepal. Universal Journal of Public Health. 2017;5(1):8-16. 